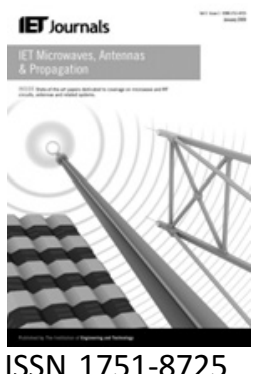

\title{
Implicit space mapping with adaptive selection of preassigned parameters
}

\section{S. Koziel ${ }^{1} \quad$ Q.S. Cheng ${ }^{2}$ J.W. Bandler ${ }^{2,3}$}

${ }^{1}$ Engineering Optimization \& Modeling Center, School of Science and Engineering, Reykjavík University, Kringlunni 1, Reykjavík IS-103, Iceland

${ }^{2}$ Simulation Optimization Systems Research Laboratory, Department of Electrical and Computer Engineering, McMaster University, Hamilton, ON L8S 4K1, Canada

${ }^{3}$ Bandler Corporation, P.O. Box 8083, Dundas, ON, Canada L9H $5 E 7$

E-mail: koziel@ru.is

\begin{abstract}
Implicit space mapping is one of the latest developments in space mapping (SM) technology. Its advantage is that the variables (the so-called preassigned parameters) used to adjust the surrogate model to have it match the fine model are typically separate from the design variables. Also, implicit space mapping offers greater flexibility in creating and enhancing surrogate models. Still, choosing the proper model as well as the right set of preassigned parameters - both being critical for the performance of the space mapping algorithm - is an open problem. Here, the authors apply suitable assessment techniques that help in automatically making the right selection of the model and, consequently, its associated parameters. The assessment is embedded into the SM algorithm so that the choice of the most suitable model is performed before each iteration of the algorithm. Our approach is verified using several microwave design optimisation problems. The authors also present a modified version of the adaptive SM to improve performance. Our examples are repeated using the modified adaptive SM and compared with the basic adaptive SM.
\end{abstract}

\section{Introduction}

Since the space mapping concept [1-5] was first developed, it has been successfully applied to microwave engineering design problems as well as in other engineering fields (e.g. [6-18]). Space mapping allows for efficient optimisation of expensive or 'fine' models by means of the iterative optimisation and updating of the so-called 'coarse' models, less accurate but cheaper to evaluate. In the microwave area, fine models are often based on full-wave electromagnetic simulations, whereas coarse models may be physically based circuit models. Much research has been carried out on various aspects of space mapping and related approaches $[3-5,19-28]$.

It should be emphasised that the coarse model being physically based is a key factor for the success of space mapping, particularly because space mapping is capable of yielding satisfactory designs after a few fine model evaluations. Many other surrogate-model-based methods
[29-34] exploit a functional surrogate that is created by direct approximation of the available fine model data, and therefore cannot compete with space mapping in terms of computational efficiency.

Among the developments in the art of space mapping, implicit space mapping $[3,7]$ is probably the simplest technique to implement. Its most characteristic feature is that the surrogate model parameters that are used to match the fine model are different from the design variables, although they are still typically physically based, for example dielectric constant and the height of the substrate. These parameters are normally selected and their values fixed early in the modelling and design process. The effects on the responses of microwave components of varying the values of these parameters may be as significant as those achieved by varying the optimisable parameters. Preassigned parameters, also known as implicit space mapping parameters, can also be introduced as synthetic parameters with no direct 
counterparts in the fine model; however, it is still advisable to keep them physically based (e.g. small inductors or capacitors that enhance the flexibility of a circuitequivalent-based coarse model). Another advantage of implicit space mapping is that, unlike input space mapping [1, 4], it does not affect the domain of the surrogate model, which may be important in the case of constrained optimisation. Implicit space mapping has been demonstrated to work both in the design [3, 7, 35, 36] and modelling [37, 38] arenas.

An open problem in space mapping optimisation, which is especially visible in implicit space mapping, is the proper selection of the coarse model and/or the corresponding set of parameters. With a large number of possible ways of choosing from already existing preassigned parameters and/ or introducing synthetic parameters it is not clear beforehand which coarse model and/or set of parameters would most suit a given design problem. A wrong selection of coarse model and preassigned parameters may result in poor performance of the implicit space mapping algorithm $[25,26,28,36]$. In particular, the algorithm may be unable to find a satisfactory solution or may exhibit slow convergence, which would make the optimisation process very expensive. Although engineering experience helps in the coarse model selection process, it does not guarantee success because the dependence between a model's desirable features (such as its approximation/generalisation ability) and its topology and/or parameters is normally complicated.

Here, we employ certain assessment methodologies that allow us to estimate the ability of the coarse model to match the fine model and to detect possible under- or over-flexibility that should be avoided in order to obtain a reasonable trade-off between the approximation and generalisation properties of the surrogate model. Given the design problem and the set of candidate coarse models, a suitable model is selected based on the values of properly designed quality factors associated with each candidate.

The paper is organised as follows. In Section 2 we recall the formulation of the implicit space mapping optimisation algorithm and discuss some practical issues related to a proper choice of preassigned parameters in the surrogate model. In Section 3 we describe an adaptive implicit space mapping algorithm that selects a surrogate model out of a set of candidate models based on their estimated approximation and generalisation properties. In Section 4 we present experimental results and compare the performance of the adaptive algorithm with the performance of the original implicit space mapping algorithm using each candidate surrogate model. A modification of the adaptive algorithm that improves the quality of the final solution found by the space mapping optimisation process is discussed in Section 5.

\section{Implicit space mapping optimisation}

\subsection{Implicit space mapping optimisation algorithm}

Our goal is to solve the following problem

$$
\boldsymbol{x}_{\mathrm{f}}^{*} \in \arg \min _{\boldsymbol{x}} U\left(\boldsymbol{R}_{\mathrm{f}}(\boldsymbol{x})\right)
$$

where $\boldsymbol{R}_{\mathrm{f}} \in R^{m}$ denotes the response vector of a fine model of the device of interest. It might be, for example the modulus of the transmission coefficient $\left|S_{21}\right|$ evaluated at $m$ different frequencies. $U$ is a given scalar merit function, for example a norm, or a minimax function with upper and lower specifications. Vector $\boldsymbol{x}_{\mathrm{f}}^{*}$ is the optimal design to be determined.

Let $\boldsymbol{R}_{\mathrm{c}} \in R^{m}$ denote the response vector of the coarse model that describes the same object as the fine model: less accurate but much faster to evaluate. We assume that $\boldsymbol{R}_{\mathrm{c}}$ depends on the two sets of parameters: (i) design variables $\boldsymbol{x}$, the same as in the fine model; and (ii) preassigned parameters $\boldsymbol{x}_{\mathrm{p}}$, that is parameters that are used to adjust the coarse model and match it to the fine model. Preassigned parameters can be parameters that are normally fixed in the fine model during the optimisation process, such as dielectric constants or thickness of the substrate, but they can be freely changed in the coarse model. Preassigned parameters can also be synthetic parameters that are introduced into the coarse model in order to increase its flexibility, even if they do not correspond to any physical parameter in the fine model. An example would be a small capacitor introduced between coupled lines in the microstrip filter model.

We consider an optimisation algorithm that generates a sequence of points $\boldsymbol{x}^{(i)}, i=1,2, \ldots$, such that

$$
\boldsymbol{x}^{(i+1)}=\arg \min _{\boldsymbol{x}} U\left(\boldsymbol{R}_{\mathrm{c}}\left(\boldsymbol{x}, \boldsymbol{x}_{\mathrm{p}}^{(i)}\right)\right)
$$

where

$$
\boldsymbol{x}_{\mathrm{p}}^{(i)}=\arg \min _{\boldsymbol{x}_{\mathrm{p}}}\left\|\boldsymbol{R}_{\mathrm{f}}\left(\boldsymbol{x}^{(i)}\right)-\boldsymbol{R}_{\mathrm{c}}\left(\boldsymbol{x}^{(i)}, \boldsymbol{x}_{\mathrm{p}}\right)\right\|
$$

Thus, the values of the preassigned parameters are updated in each iteration of the implicit space mapping algorithm in order to obtain the best possible match with the fine model at the current design. The next design is the optimal solution of the current surrogate model. Initial values of the preassigned parameters $x_{\mathrm{p}}^{(0)}$ are normally the same as the corresponding parameters in the fine model or are set to zero for synthetic parameters. 


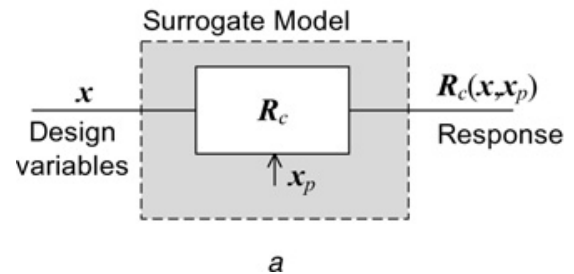

a

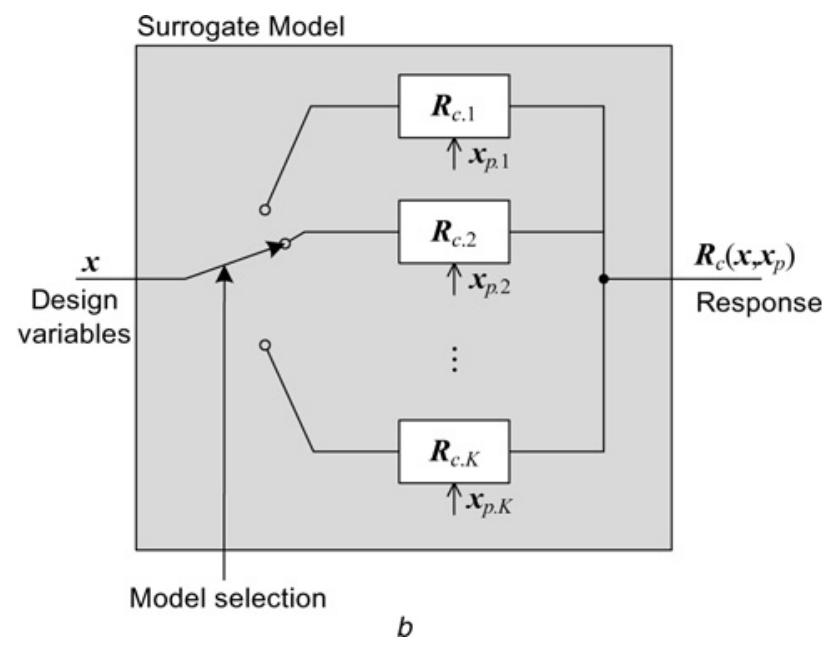

Figure 1 Implicit space mapping surrogate model

a Traditional, single-coarse-model approach

$b$ Adaptive implicit space mapping: the surrogate model is selected out of the set of candidate models using suitable performance criteria

In order to improve the performance of the implicit space mapping algorithm, an output space mapping correction term [4] can be used to enhance the coarse model so that formula (2) is replaced by

$$
\boldsymbol{x}^{(i+1)}=\arg \min _{\boldsymbol{x}} U\left(\boldsymbol{R}_{\mathrm{c}}\left(\boldsymbol{x}, \boldsymbol{x}_{\mathrm{p}}^{(i)}\right)+\Delta \boldsymbol{R}^{(i)}\right)
$$

where

$$
\Delta \boldsymbol{R}^{(i)}=\boldsymbol{R}_{\mathrm{f}}\left(\boldsymbol{x}^{(i)}\right)-\boldsymbol{R}_{\mathrm{c}}\left(\boldsymbol{x}^{(i)}, \boldsymbol{x}_{\mathrm{p}}^{(i)}\right)
$$

The overall surrogate model $\boldsymbol{R}_{\mathrm{c}}\left(\boldsymbol{x}, \boldsymbol{x}_{\mathrm{p}}^{(i)}\right)+\Delta \boldsymbol{R}^{(i)}$ satisfies a zero-order consistency condition with the fine model, that is we have $\boldsymbol{R}_{\mathrm{c}}\left(\boldsymbol{x}^{(i)}, \boldsymbol{x}_{\mathrm{p}}^{(i)}\right)+\Delta \boldsymbol{R}^{(i)}=\boldsymbol{R}_{\mathrm{f}}\left(\boldsymbol{x}^{(i)}\right)$, which, in general, improves the ability of the space mapping algorithm to find a fine model optimum with better accuracy [4].

Convergence properties of the space mapping algorithm can be improved by using the trust region method [39, 40], in which the surrogate model optimisation is restricted to the neighbourhood of the point $\boldsymbol{x}^{(i)}$ so that (2) is replaced by

$$
\boldsymbol{x}^{(i+1)}=\arg \min _{\boldsymbol{x},\left\|\boldsymbol{x}-\boldsymbol{x}^{(i)}\right\| \leq \delta^{(i)}} U\left(\boldsymbol{R}_{\mathrm{c}}\left(\boldsymbol{x}, \boldsymbol{x}_{\mathrm{p}}^{(i)}\right)\right)
$$

where $\delta^{(i)}$ denotes the trust region radius at iteration $i$, which is updated at every iteration using classical rules [39]. The trust-region-based version of (4) is

$$
\boldsymbol{x}^{(i+1)}=\arg \min _{\boldsymbol{x},\left\|\boldsymbol{x}-\boldsymbol{x}^{(i)}\right\| \leq \delta^{(i)}} U\left(\boldsymbol{R}_{\mathrm{c}}\left(\boldsymbol{x}, \boldsymbol{x}_{\mathrm{p}}^{(i)}\right)+\Delta \boldsymbol{R}^{(i)}\right)
$$

\subsection{Coarse models and preassigned parameters}

It is well known $[25,26,28]$ that the performance of space mapping algorithms heavily depends on the quality of the coarse model utilised in the optimisation process and the type of mapping involved to create the surrogate model. Normally, a suitable choice of the coarse model and space mapping type is problem dependent and requires both knowledge of the problem and engineering experience, although there are some methods available (e.g. $[25,26]$ ) that allow us to make this choice automatic to some extent. Another issue is that the convergence of the space mapping algorithm is not guaranteed in general [28]. It is also dependent on a proper choice of the coarse model and the space mapping surrogate.

These problems are even more visible in the case of implicit space mapping. The reason is that the number of possible ways of choosing from already existing preassigned parameters and/or introducing synthetic parameters is virtually unlimited. Engineering experience can help in this process; however, it does not guarantee success. It seems that a much better way is through suitable assessment methodologies that not only estimate the ability of the surrogate model to match the fine model but can detect possible under- or over-flexibility that is to be avoided in order to obtain a reasonable trade-off between the approximation and generalisation properties of the surrogate model.

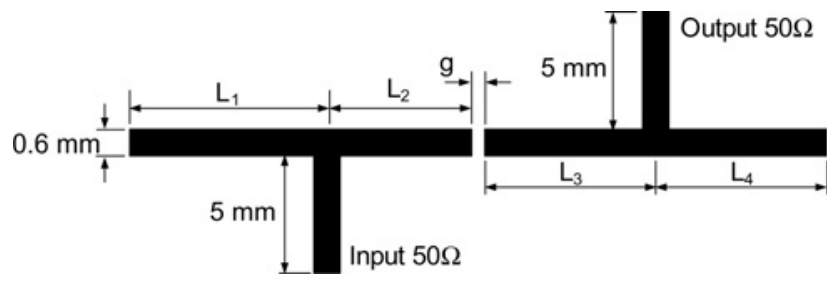

Figure 2 Microstrip bandpass filter: geometry [41] 


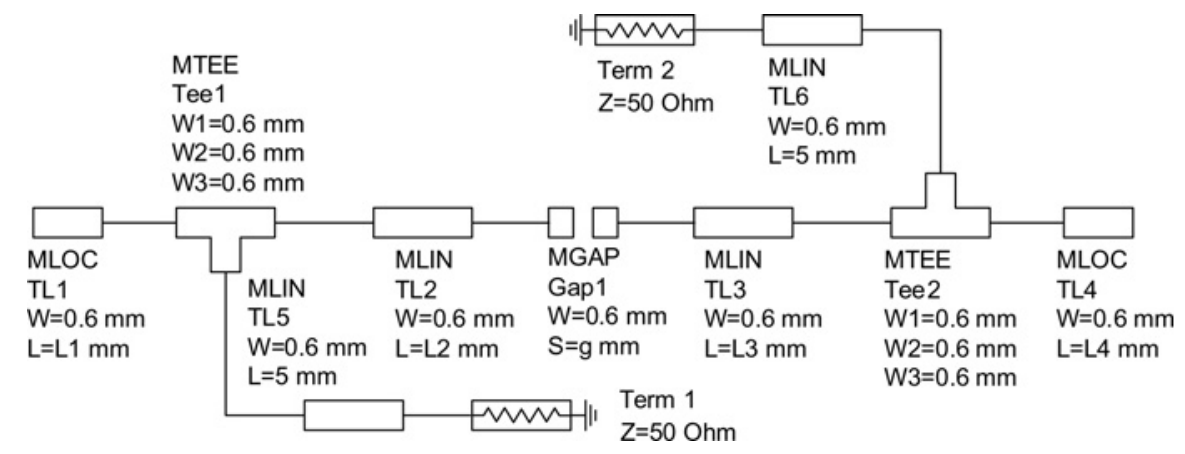

Figure 3 Microstrip bandpass filter: coarse model (Agilent ADS)

\section{Selecting parameters of the surrogate model: adaptive space mapping algorithm}

Suppose that we have a set of candidate coarse models $\boldsymbol{R}_{\mathrm{c} . j}, j=1,2, \ldots, K$, and we want to know which is suitable for a surrogate model at any given iteration of the implicit space mapping optimisation algorithm. Each coarse model has a corresponding set of preassigned parameters. We will denote by $\boldsymbol{x}_{j}^{(0)}$ the initial values of these parameters for model $\boldsymbol{R}_{\mathrm{c} . j}$. In general, the candidate models may be different both with respect to the structure (in particular, they may be different equivalent circuit realisations of the same microwave structure) and with respect to the choice of preassigned parameters.

We adopt an adaptive space mapping algorithm [25]. Let $X^{(i)}=\left\{\boldsymbol{x}^{(0)}, \boldsymbol{x}^{(1)}, \ldots, \boldsymbol{x}^{(i)}\right\}$ be the set of all previous iteration points found by the space mapping algorithm. At iteration $i$, we perform, for each candidate model, extraction of its parameters using the fine model data at point $\boldsymbol{x}^{(i)}$ as follows

$$
\boldsymbol{x}_{\mathrm{p} . j}^{(i)}=\arg \min _{\boldsymbol{x}_{\mathrm{p}}}\left\|\boldsymbol{R}_{\mathrm{f}}\left(\boldsymbol{x}^{(i)}\right)-\boldsymbol{R}_{\mathrm{c} . j}\left(\boldsymbol{x}^{(i)}, \boldsymbol{x}_{\mathrm{p}}\right)\right\|
$$

Now, for each model, we define two quality factors

$$
\begin{gathered}
F_{\mathrm{APP} . j}^{(i)}=\frac{\left\|\boldsymbol{R}_{\mathrm{f}}\left(\boldsymbol{x}^{(i)}\right)-\boldsymbol{R}_{\mathrm{c} . j}\left(\boldsymbol{x}^{(i)}, \boldsymbol{x}_{j}^{(0)}\right)\right\|}{\left\|\boldsymbol{R}_{\mathrm{f}}\left(\boldsymbol{x}^{(i)}\right)-\boldsymbol{R}_{\mathrm{c} . j}\left(\boldsymbol{x}^{(i)}, \boldsymbol{x}_{\mathrm{p} . j}^{(i)}\right)\right\|} \\
F_{\mathrm{GEN} . j}^{(i)}=\frac{\left\|\boldsymbol{R}_{\mathrm{f}}\left(\boldsymbol{x}^{(i-1)}\right)-\boldsymbol{R}_{\mathrm{c} . j}\left(\boldsymbol{x}^{(i-1)}, \boldsymbol{x}_{j}^{(0)}\right)\right\|}{\left\|\boldsymbol{R}_{\mathrm{f}}\left(\boldsymbol{x}^{(i-1)}\right)-\boldsymbol{R}_{\mathrm{c} . j}\left(\boldsymbol{x}^{(i-1)}, \boldsymbol{x}_{\mathrm{p} . j}^{(i)}\right)\right\|}
\end{gathered}
$$

If $i=0$, we only calculate $F_{\mathrm{APP} . j}^{(i)}$ and set $F_{\mathrm{GEN} . j}^{(i)}=F_{\mathrm{APP} . j}^{(i)}$.

The first factor, $F_{\mathrm{APP} . j}^{(i)}$, measures the approximation properties of model $\boldsymbol{R}_{\mathrm{c} . j}$, because it is the ratio of the matching error before and after parameter extraction, calculated for the point that was used in parameter

\begin{tabular}{|c|c|c|}
\hline \multirow{2}{*}{$\begin{array}{c}\text { Candidate } \\
\text { model }\end{array}$} & \multicolumn{2}{|r|}{ Preassigned parameters } \\
\hline & $\begin{array}{l}\text { Number of } \\
\text { parameters }\end{array}$ & List of parameters ${ }^{a}$ \\
\hline $\boldsymbol{R}_{\text {c. } 1}$ & 2 & $\begin{array}{c}\varepsilon_{r}=\varepsilon_{r . \mathrm{TL} 1}=\varepsilon_{r . \mathrm{TL} 2}=\varepsilon_{r . \mathrm{TL} 3}=\varepsilon_{r . \mathrm{TL} 4}=\varepsilon_{r . \mathrm{TL} 5}=\varepsilon_{r . \mathrm{TL} 6}=\varepsilon_{r . \mathrm{Gap} 1}=\varepsilon_{r . \mathrm{Tee} 1}=\varepsilon_{r . \mathrm{Tee} 2}, \\
H=H_{\mathrm{TL} 1}=H_{\mathrm{TL} 2}=H_{\mathrm{TL} 3}=H_{\mathrm{TL} 4}=H_{\mathrm{TL} 5}=H_{\mathrm{TL} 6}=H_{\mathrm{Gap} 1}=H_{\mathrm{Tee} 1}=H_{\mathrm{Tee} 2}\end{array}$ \\
\hline $\boldsymbol{R}_{\mathrm{c.2}}$ & 18 & $\begin{array}{c}\varepsilon_{r . \mathrm{TL} 1}, \varepsilon_{r . \mathrm{TL} 2}, \varepsilon_{r . \mathrm{TL} 3}, \varepsilon_{r . \mathrm{TL} 4}, \varepsilon_{r . \mathrm{TL} 5}, \varepsilon_{r . \mathrm{TL} 6}, \varepsilon_{r . \mathrm{Gap} 1}, \varepsilon_{r . \mathrm{Tee} 1}, \varepsilon_{r . \mathrm{Tee} 2}, H_{\mathrm{TL} 1}, H_{\mathrm{TL} 2}, \\
H_{\mathrm{TL} 3}, H_{\mathrm{TL} 4}, H_{\mathrm{TL} 5}, H_{\mathrm{TL} 6}, H_{\mathrm{Gap} 1}, H_{\mathrm{Tee} 1}, H_{\mathrm{Tee} 2}\end{array}$ \\
\hline $\boldsymbol{R}_{\mathrm{c} .3}$ & 10 & $\varepsilon_{r . \mathrm{TL} 1}, \varepsilon_{r . \mathrm{TL} 2}, \varepsilon_{r . \mathrm{TL} 3}, \varepsilon_{r . \mathrm{TL} 4}, \varepsilon_{r . \mathrm{Gap} 1}, H_{\mathrm{TL} 1}, H_{\mathrm{TL} 2}, H_{\mathrm{TL} 3}, H_{\mathrm{TL} 4}, H_{\mathrm{Gap} 1}$ \\
\hline $\boldsymbol{R}_{\mathrm{c} .4}$ & 5 & $\varepsilon_{r . \mathrm{TL} 1}, \varepsilon_{r . \mathrm{TL} 2}, \varepsilon_{r . \mathrm{TL} 3}, \varepsilon_{r . \mathrm{TL} 4}, H_{\mathrm{Gap} 1}$ \\
\hline $\boldsymbol{R}_{\mathrm{c} .5}$ & 6 & $\varepsilon_{r . \mathrm{TL} 1}, \varepsilon_{r . \mathrm{TL} 2}, \varepsilon_{r . \mathrm{TL} 3}, \varepsilon_{r . \mathrm{TL} 4}, \varepsilon_{r . \mathrm{Gap} 1}, H_{\mathrm{Gap} 1}$ \\
\hline
\end{tabular}
extraction. The second factor, $F_{\mathrm{GEN} . j}^{(i)}$, measures the

Table 1 Parameters of the candidate models used in the microstrip bandpass filter problem

${ }^{\mathrm{a}}$ Symbols $\varepsilon_{r \text {.Elem }}$ and $H_{\text {Elem }}$ refer to the dielectric constant (initial value 9) and substrate height (initial value $0.66 \mathrm{~mm}$ ) of element Elem, respectively. 
extrapolation (generalisation) properties of model $\boldsymbol{R}_{\mathrm{c} . j}$, because it is the ratio of the matching error before and after parameter extraction, calculated for the point that was not used in the extraction process.

At iteration $i$, we select the coarse model based on the combined quality factor

$$
F_{j}^{(i)}=\alpha F_{\mathrm{APP} . j}^{(i)}+(1-\alpha) F_{\mathrm{GEN} . j}^{(i)}
$$

In particular, we set

$$
\boldsymbol{R}_{\mathrm{c}}\left(\boldsymbol{x}, \boldsymbol{x}_{\mathrm{p}}^{(i)}\right)=\boldsymbol{R}_{\mathrm{c} \cdot j_{\max }}\left(\boldsymbol{x}, \boldsymbol{x}_{\mathrm{p} \cdot j_{\max }}^{(i)}\right)
$$

where

$$
j_{\max }=\arg \max _{j \in\{1,2, \ldots, K\}} F_{j}^{(i)}
$$

A good surrogate model exhibits high values for both $F_{\mathrm{APP} . j}^{(i)}$ and $F_{\mathrm{GEN} . j}^{(i)}$, however, we consider generalisation properties as even more important than approximation properties because $F_{\mathrm{GEN} . j}^{(i)}$ indicates the capability of modelling the fine model outside the points at which the surrogate was created. Also, this factor indicates potential over-flexibility of the surrogate model. Therefore, in practice, we use small values of $\alpha$ (e.g. $\alpha=0.1$ ) [25]. In general, the value of $\alpha$ could be determined by some kind of heuristic procedure, however, we keep $\alpha$ fixed throughout the algorithm here.

Fig. 1 illustrates the difference between the traditional space mapping approach and adaptive implicit space mapping algorithm in terms of setting up and selecting the surrogate model.

Table 2 Results of implicit space mapping optimisation of the microstrip bandpass filter

\begin{tabular}{|l|c|c|}
\hline $\begin{array}{c}\text { Surrogate } \\
\text { model }\end{array}$ & $\begin{array}{c}\text { Specification error at } \\
\text { final solution (dB) }\end{array}$ & $\begin{array}{c}\text { Number of fine } \\
\text { model evaluations }\end{array}$ \\
\hline $\boldsymbol{R}_{\mathrm{c} .1}$ & +1.3 & 7 \\
\hline $\boldsymbol{R}_{\mathrm{c} .2}$ & +0.1 & 6 \\
\hline $\boldsymbol{R}_{\mathrm{c} .3}$ & -1.2 & 8 \\
\hline $\boldsymbol{R}_{\mathrm{c} .4}$ & -1.0 & 6 \\
\hline $\boldsymbol{R}_{\mathrm{c} .5}$ & -0.9 & 8 \\
\hline $\begin{array}{l}\text { adaptive } \\
\text { algorithm }\end{array}$ & -1.2 & 8 \\
\hline
\end{tabular}

Table 3 Surrogate model evolution for the microstrip bandpass filter problem

\begin{tabular}{|l|c|r|l|}
\hline Iteration number & Surrogate model & $F_{j_{\max }^{(i)}}$ & $\overline{F^{(i)}}$ \\
\hline 1 & $\boldsymbol{R}_{\text {c. } 3}$ & 90.1 & 59.5 \\
\hline 2 & $\boldsymbol{R}_{\text {c. } 3}$ & 289.3 & 81.8 \\
\hline 3 & $\boldsymbol{R}_{\text {c. } 4}$ & 36.5 & 22.9 \\
\hline 4 & $\boldsymbol{R}_{\text {c. } 4}$ & 29.5 & 19.4 \\
\hline $\begin{array}{l}{ }^{\mathrm{a}} \overline{F^{(i)}}=K^{-1} \sum_{j=1}^{K} F_{j}^{(i)} \text { is the average combined quality } \\
\text { factor }\end{array}$
\end{tabular}

The implicit space mapping algorithm with automatic selection of the coarse model can be summarised as follows:

Step 0: Set the starting point $\boldsymbol{x}^{(0)}$; Choose the candidate coarse model set $\left\{R_{\mathrm{c} .1}, \ldots, R_{\mathrm{c} . K}\right\}$ with initial values of the preassigned parameters $\boldsymbol{x}_{j}^{(0)}$ for the $j$ th model; Set $i=0$; Evaluate $\boldsymbol{R}_{\mathrm{f}}$ at $\boldsymbol{x}^{(0)}$

Step 1: Calculate the quality factors $F_{\mathrm{APP} . j}^{(i)}$ and $F_{\mathrm{GEN} . j}^{(i)}$, $j=1, \ldots, K$, as in (8) - (10); Calculate the combined quality factors $F_{j}^{(i)}, j=1, \ldots, K$, as in (11);

Step 2: Select the current model index $j_{\max }=\arg \max _{j \in\{1, \ldots, K\}} F_{j}^{(i)}$

Step 3: Obtain the new design $x^{(i+1)}=\arg \min _{x}$

$U\left(\boldsymbol{R}_{\mathrm{c} . j_{\max }}\left(\boldsymbol{x}, \boldsymbol{x}_{\mathrm{p} . j_{\max }}^{(i)}\right)\right)$;

Step 4: Evaluate $R_{\mathrm{f}}$ at $\boldsymbol{x}^{(i+1)}$;

Step 5: Set $i=i+1$;

Step 6: If the termination condition is not satisfied go to Step 1; else terminate the algorithm.

Note that the adaptive algorithm (14) does not require any extra fine model evaluations because the coarse model assessment is based on already existing fine model data. Additional computational effort concerns the coarse model

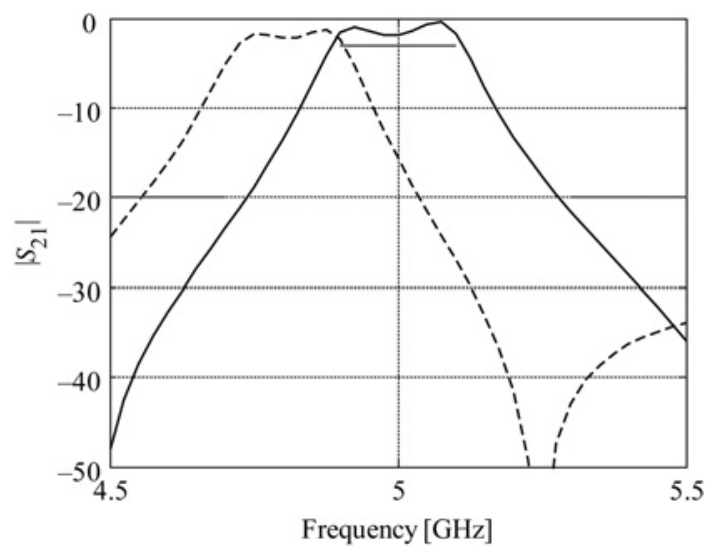

Figure 4 Microstrip bandpass filter: initial solution (dashed line), and final solution (solid line) found using the adaptive implicit space mapping algorithm 
only, and because we assume that the coarse model evaluation is significantly cheaper than the fine model evaluation, this additional effort should not substantially affect the total execution time of the optimisation algorithm.

\section{Verification examples}

In this section we verify the performance of the adaptive implicit space mapping algorithm and compare it with the performance of the space mapping algorithm using a fixed surrogate model. We use three examples of microwave design optimisation problems.

\subsection{Microstrip bandpass filter [41]}

Consider the microstrip bandpass filter [41] (Fig. 2). The design parameters are $x=\left[\begin{array}{llll}L_{1} & L_{2} & L_{3} & L_{4} \\ \mathrm{~g}\end{array}\right]^{\mathrm{T}}$. The fine model
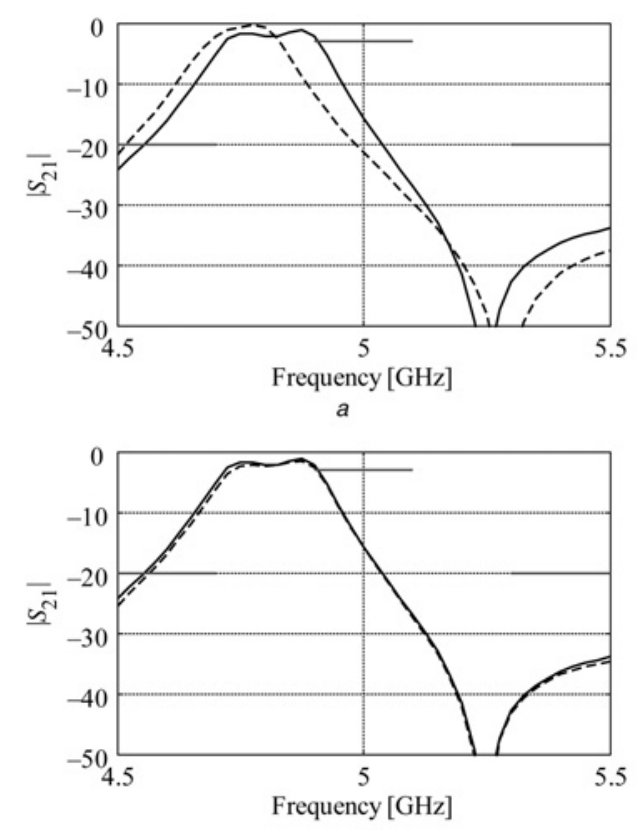

$c$

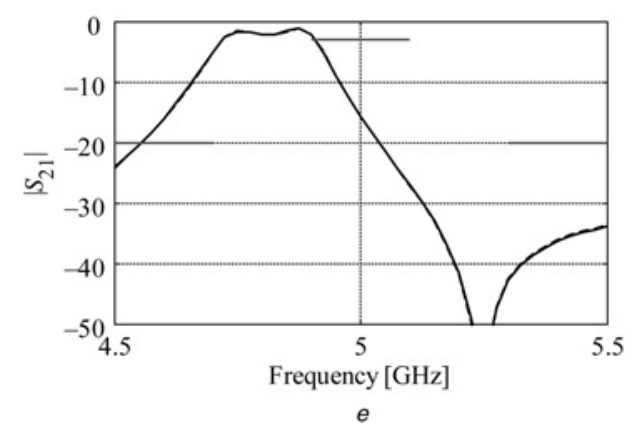

is simulated in FEKO [42], the coarse model is the circuit model implemented in Agilent ADS [43] (Fig. 3). The design specifications are $\left|S_{21}\right| \leq-20 \mathrm{~dB}$ for $4.5 \mathrm{GHz} \leq \omega \leq 4.7 \mathrm{GHz}$ and $5.3 \mathrm{GHz} \leq \omega \leq 5.5 \mathrm{GHz}$ and $\left|S_{21}\right| \geq-3 \mathrm{~dB}$ for $4.9 \mathrm{GHz} \leq \omega \leq 5.1 \mathrm{GHz}$. The initial design is the coarse model optimal solution $x^{(0)}=[6.784$ $4.8906 .2565 .280 .0956]^{\mathrm{T}} \mathrm{mm}$ (specification error $+24 \mathrm{~dB}$ ).

The filter was optimised using the adaptive implicit SM algorithm of Section 3, and the trust region approach to improve convergence [cf. (6)]. We considered five candidate models, that is the coarse model of Fig. 3 with five sets of preassigned parameters as described in Table 1. For comparison purposes, the standard implicit SM optimisation was also performed on each candidate model individually. The optimisation results are summarised in Table 2. Table 3 shows
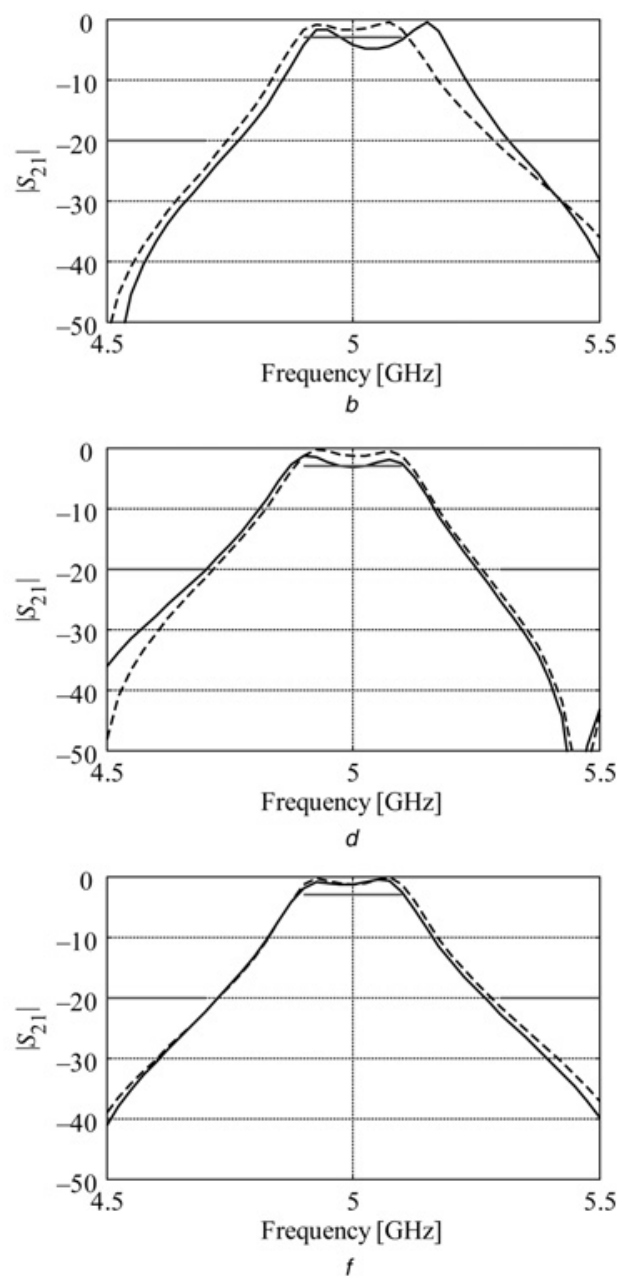

Figure 5 Responses of the fine model (solid line) and the surrogate model (dashed line) for the microstrip bandpass filter example:

$a$ responses at the initial design for $\boldsymbol{R}_{\mathrm{c} .1}$

$b$ responses at the optimised surrogate model design for $\boldsymbol{R}_{\mathrm{c} .1}$

$c$ responses at the initial design for $\boldsymbol{R}_{\mathrm{c} .2}$

$d$ responses at the optimised surrogate model design for $\boldsymbol{R}_{\mathrm{c} .2}$

$\boldsymbol{e}$ responses at the initial design for $\boldsymbol{R}_{\mathrm{c} .3}$

$f$ responses at the optimised surrogate model design for $\boldsymbol{R}_{\mathrm{c} .3}$

$\boldsymbol{R}_{\mathrm{c} .1}$ shows poor overall matching with the fine model. $\boldsymbol{R}_{\mathrm{c} .2}$ shows very good approximation but degraded generalisation capability. $\boldsymbol{R}_{\mathrm{c} .3}$ exhibits both good approximation and generalisation capabilities 


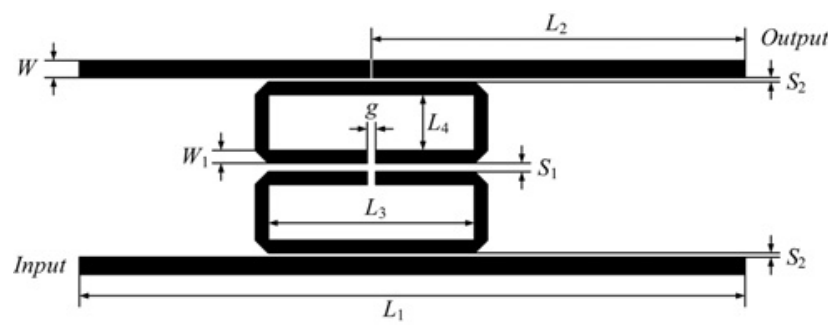

Figure 6 Open-loop ring resonator bandpass filter: geometry [44]

the actual sequence of candidate models selected in subsequent iterations of the algorithm. The number of iterations does not correspond to the number of fine model evaluations shown in Table 2 as there may be more than one fine model evaluation per iteration because of the trust region approach. Fig. 4 shows the fine model response at the initial solution $x^{(0)}$ and at the final design obtained using our adaptive algorithm, $x^{(4)}=\left[\begin{array}{lllll}6.337 & 4.884 & 6.212 & 4.857 & 0.097\end{array}\right]^{\mathrm{T}} \mathrm{mm}$ (specification error $-1.2 \mathrm{~dB}$ ). The space mapping algorithm was terminated if one of the following conditions was satisfied: (i) $\left\|x^{(i)}-x^{(i-1)}\right\|<10^{-3}$ or (ii) the trust region size, $\delta^{(i)}<10^{-3}$.

The results shown in Table 2 indicate that the algorithm working with the adaptive model selection performs as good as the best algorithms using a fixed surrogate model. Note that some of the SM algorithms with fixed model failed to find an acceptable solution. In particular, this applies to the simplest model $\boldsymbol{R}_{\text {c.1 }}$ (only two preassigned parameters) and to the most complex model $\boldsymbol{R}_{\text {c.2 }}$ (18 preassigned parameters). This confirms that a proper selection of the set of preassigned parameter is not obvious.

Fig. 5 shows the fine model response and the surrogate model response (after the parameter extraction) at the initial design, and the optimised surrogate model response as well as the corresponding fine model response for the candidate models $\boldsymbol{R}_{\text {c. } 1}, \boldsymbol{R}_{\mathrm{c} .2}$ and $\boldsymbol{R}_{\mathrm{c} .3}$. We can observe that model $\boldsymbol{R}_{\text {c.1 }}$ exhibits poor overall matching with the fine model. Model $\boldsymbol{R}_{\text {c. } 2}$ shows a very good match at the initial design, however, there is a significant discrepancy at the optimised design of this surrogate. This indicates that model $\boldsymbol{R}_{\text {c. } 2}$ is over-flexible: the large number of parameters degrades its generalisation capabilities. Model $\boldsymbol{R}_{\mathrm{c} .3}$, on the other hand, demonstrates both good approximation and generalisation capability.

\subsection{Open-loop ring resonator bandpass filter [44]}

Consider the open-loop ring resonator bandpass filter [44] shown in Fig. 6. The design parameters are $x=\left[\begin{array}{lll}L_{1} & L_{2} & L_{3}\end{array}\right.$ $\left.L_{4} S_{1} S_{2} g\right]^{\mathrm{T}} \mathrm{mm}$. Other parameter values are $W=0.6 \mathrm{~mm}$ and $W_{1}=0.4 \mathrm{~mm}$. The fine model is simulated in FEKO [42]. The coarse model is the circuit model implemented in Agilent ADS [43] (Fig. 7). The design specifications are $\left|S_{21}\right| \geq-3 \mathrm{~dB}$ for $2.8 \mathrm{GHz} \leq \omega \leq 3.2 \mathrm{GHz}$, and $\left|S_{21}\right| \leq$

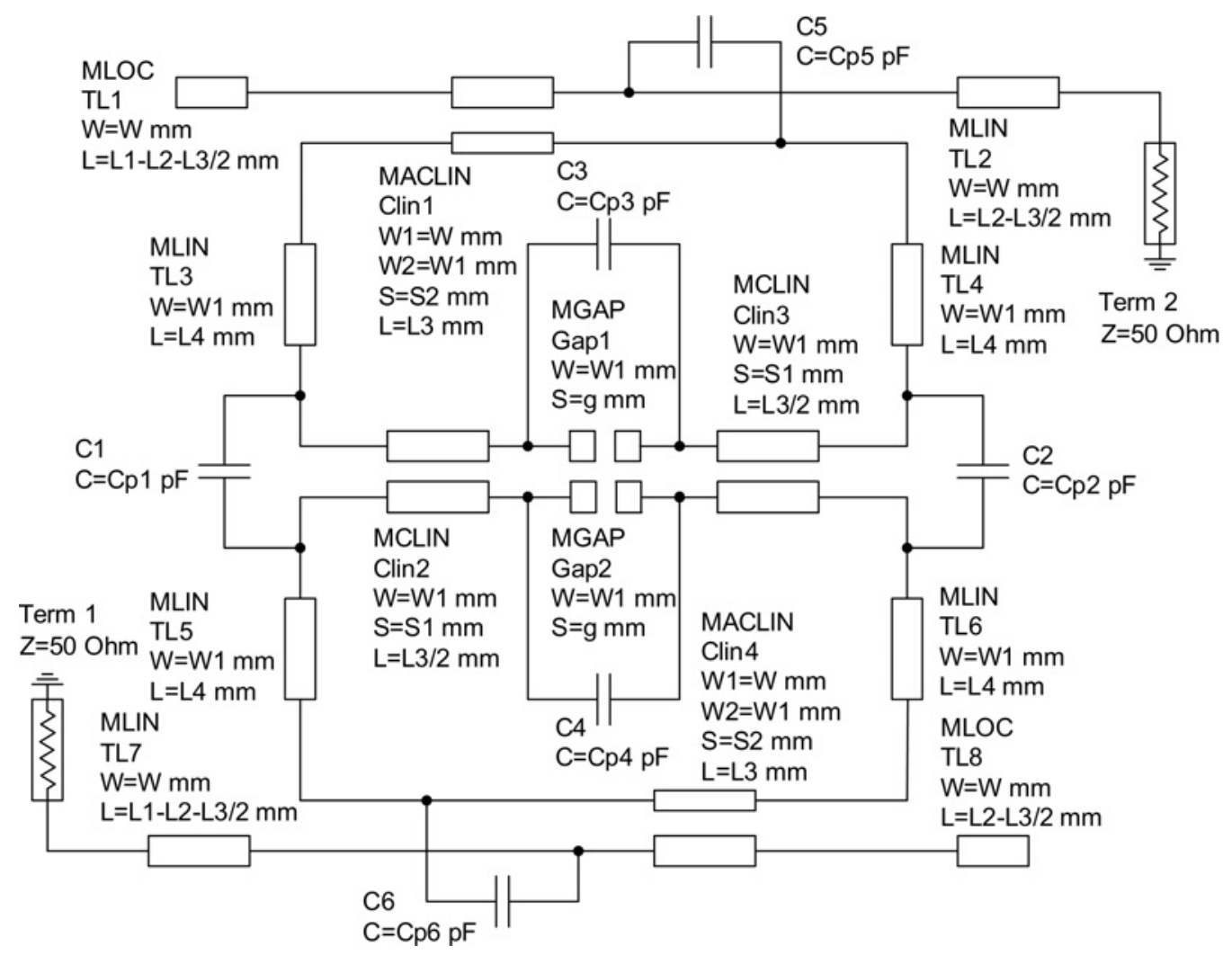

Figure 7 Open-loop ring resonator bandpass filter: coarse model (Agilent ADS) 
Table 4 Candidate model parameters used in the open-loop ring resonator bandpass filter problem

\begin{tabular}{|c|c|c|}
\hline \multirow{2}{*}{$\begin{array}{l}\text { Candidate } \\
\text { model }\end{array}$} & \multicolumn{2}{|r|}{ Preassigned parameters } \\
\hline & $\begin{array}{l}\text { Number of } \\
\text { parameters }\end{array}$ & List of parameters ${ }^{a}$ \\
\hline $\boldsymbol{R}_{\mathrm{c} .1}$ & 2 & $\begin{array}{c}\varepsilon_{r}=\varepsilon_{r . \mathrm{TL} 1}=\ldots=\varepsilon_{r . \mathrm{TL} 8}=\varepsilon_{r . \mathrm{Gap} 1}=\varepsilon_{r . \mathrm{Gap} 2}=\varepsilon_{r . \mathrm{Clin} 1}=\ldots=\varepsilon_{r . \mathrm{Clin} 4}, \\
H=H_{\mathrm{TL} 1}=\ldots=H_{\mathrm{TL} 8}=H_{\mathrm{Gap} 1}=H_{\mathrm{Gap} 2}=H_{\mathrm{Clin} 1}=\ldots=H_{\mathrm{Clin} 4} \\
\text { capacitor values } C_{p 1}=\ldots=C_{p 6}=0\end{array}$ \\
\hline $\boldsymbol{R}_{\mathrm{c} .2}$ & 6 & $\begin{array}{c}\varepsilon_{r 1}=\varepsilon_{r . \mathrm{TL} 1}=\varepsilon_{r . \mathrm{TL} 3}=\varepsilon_{r . \mathrm{Clin} 1}, \varepsilon_{r 2}=\varepsilon_{r . \mathrm{TL} 3}=\varepsilon_{r . \mathrm{TL} 4}, \varepsilon_{r 3}=\varepsilon_{r . \mathrm{Clin} 2}=\varepsilon_{r . \mathrm{Clin} 3} \\
=\varepsilon_{r . \mathrm{Gap} 1}=\varepsilon_{r . \mathrm{Gap} 2}, \varepsilon_{r 4}=\varepsilon_{r . \mathrm{TL} 5}=\varepsilon_{r . \mathrm{TL} 6}, \varepsilon_{r 5}=\varepsilon_{r . \mathrm{TL} 7}=\varepsilon_{r . \mathrm{TL} 8}=\varepsilon_{r . \mathrm{Clin} 4}, \\
H=H_{\mathrm{TL} 1}=\ldots=H_{\mathrm{TL} 8}=H_{\mathrm{Gap} 1}=H_{\mathrm{Gap} 2}=H_{\mathrm{Clin} 1}=\ldots=H_{\mathrm{Clin} 4} \\
\text { capacitor values } C_{p 1}=\ldots=C_{p 6}=0\end{array}$ \\
\hline $\boldsymbol{R}_{\mathrm{c} .3}$ & 10 & $\begin{array}{c}\varepsilon_{r 1}=\varepsilon_{r . \mathrm{TL} 1}=\varepsilon_{r . \mathrm{TL} 3}=\varepsilon_{r . \mathrm{Clin} 1}, \varepsilon_{r 2}=\varepsilon_{r . \mathrm{TL} 3}=\varepsilon_{r . \mathrm{TL} 4}, \varepsilon_{r 3}=\varepsilon_{r . \mathrm{Clin} 2}=\varepsilon_{r . \mathrm{Clin} 3} \\
=\varepsilon_{r . \mathrm{Gap} 1}=\varepsilon_{r . \mathrm{Gap} 2}, \varepsilon_{r 4}=\varepsilon_{r . \mathrm{TL} 5}=\varepsilon_{r . \mathrm{TL} 6}, \varepsilon_{r 5}=\varepsilon_{r . \mathrm{TL} 7}=\varepsilon_{r . \mathrm{TL} 8}=\varepsilon_{r . \mathrm{Clin} 4} \\
H_{1}=H_{\mathrm{TL} 1}=H_{\mathrm{TL} 3}=H_{\mathrm{Clin} 1}, H_{2}=H_{\mathrm{TL} 3}=H_{\mathrm{TL} 4}, H_{3}=H_{\mathrm{Clin} 2}=H_{\mathrm{Clin} 3}=H_{\mathrm{Gap} 1} \\
=H_{\mathrm{Gap} 2}, H_{4}=H_{\mathrm{TL} 5}=H_{\mathrm{TL} 6}, H_{5}=H_{\mathrm{TL} 7}=H_{\mathrm{TL} 8}=H_{\mathrm{Clin} 4} \\
\text { capacitor values } C_{p 1}=\ldots=C_{p 6}=0\end{array}$ \\
\hline $\boldsymbol{R}_{\mathrm{c} .4}$ & 12 & $\begin{aligned} \varepsilon_{r 1}= & \varepsilon_{r . \mathrm{TL} 1}=\varepsilon_{r . \mathrm{TL} 3}=\varepsilon_{r . \mathrm{Clin} 1}, \varepsilon_{r 2}=\varepsilon_{r . \mathrm{TL} 3}=\varepsilon_{r . \mathrm{TL} 4}, \varepsilon_{r 3}=\varepsilon_{r . \mathrm{Clin} 2}=\varepsilon_{r . \mathrm{Clin} 3}=\varepsilon_{r . \mathrm{Gap} 1} \\
= & \varepsilon_{r . \mathrm{Gap} 2}, \varepsilon_{r 4}=\varepsilon_{r . \mathrm{TL} 5}=\varepsilon_{r . \mathrm{TL} 6}, \varepsilon_{r 5}=\varepsilon_{r . \mathrm{TL} 7}=\varepsilon_{r . \mathrm{TL} 8}=\varepsilon_{r . \mathrm{Clin} 4}, H=H_{\mathrm{TL} 1}=\ldots \\
& =H_{\mathrm{TL} 8}=H_{\mathrm{Gap} 1}=H_{\mathrm{Gap} 2}=H_{\mathrm{Clin} 1}=\ldots=H_{\mathrm{Clin} 4}, C_{p 1}, C_{p 2}, C_{p 3}, C_{p 4}, C_{p 5}, C_{p 6}\end{aligned}$ \\
\hline $\boldsymbol{R}_{\text {c. } 5}$ & 8 & $\begin{array}{l}\varepsilon_{r}=\varepsilon_{r . \mathrm{TL} 1}=\ldots=\varepsilon_{r . \mathrm{TL} 8}=\varepsilon_{r . \mathrm{Gap} 1}=\varepsilon_{r . \mathrm{Gap} 2}=\varepsilon_{r . \mathrm{Clin} 1}=\ldots=\varepsilon_{r . \mathrm{Clin} 4}, H=H_{\mathrm{TL} 1} \\
=\ldots=H_{\mathrm{TL} 8}=H_{\mathrm{Gap} 1}=H_{\mathrm{Gap} 2}=H_{\mathrm{Clin} 1}=\ldots=H_{\mathrm{Clin} 4}, C_{p 1}, C_{p 2}, C_{p 3}, C_{p 4}, C_{p 5}, C_{p 6}\end{array}$ \\
\hline $\boldsymbol{R}_{\text {c. } 6}$ & 16 & $\begin{array}{c}\varepsilon_{r 1}=\varepsilon_{r . \mathrm{TL} 1}=\varepsilon_{r . \mathrm{TL} 3}=\varepsilon_{r . \mathrm{Clin} 1}, \varepsilon_{r 2}=\varepsilon_{r . \mathrm{TL} 3}=\varepsilon_{r . \mathrm{TL} 4}, \varepsilon_{r 3}=\varepsilon_{r . \mathrm{Clin} 2}=\varepsilon_{r . \mathrm{Clin} 3}=\varepsilon_{r . \mathrm{Gap} 1} \\
=\varepsilon_{r . \mathrm{Gap} 2}, \varepsilon_{r 4}=\varepsilon_{r . \mathrm{TL} 5}=\varepsilon_{r . \mathrm{TL} 6}, \varepsilon_{r 5}=\varepsilon_{r . \mathrm{TL} 7}=\varepsilon_{r . \mathrm{TL} 8}=\varepsilon_{r . \mathrm{Clin} 4}, H_{1}=H_{\mathrm{TL} 1}=H_{\mathrm{TL} 3} \\
=H_{\mathrm{Clin} 1}, H_{2}=H_{\mathrm{TL} 3}=H_{\mathrm{TL} 4}, H_{3}=H_{\mathrm{Clin} 2}=H_{\mathrm{Clin} 3}=H_{\mathrm{Gap} 1}=H_{\mathrm{Gap} 2}, H_{4}=H_{\mathrm{TL} 5} \\
=H_{T L 6}, H_{5}=H_{\mathrm{TL} 7}=H_{\mathrm{TL} 8}=H_{\mathrm{Clin} 4}, C_{p 1}, C_{p 2}, C_{p 3}, C_{p 4}, C_{p 5}, C_{p 6}\end{array}$ \\
\hline
\end{tabular}

${ }^{\text {a Symbols }} \varepsilon_{r \text {.Elem }}$ and $H_{\text {Elem }}$ refer to the dielectric constant (initial value 10.2 ) and substrate height (initial value $0.635 \mathrm{~mm}$ ) of element Elem, respectively

$-20 \mathrm{~dB}$ for $2.0 \mathrm{GHz} \leq \omega \leq 2.5 \mathrm{GHz}$ and $3.5 \mathrm{GHz} \leq$ $\omega \leq 4.0 \mathrm{GHz}$. The initial design is the coarse model optimal solution $x^{(0)}=\left[\begin{array}{lllll}39.62 & 8.412 & 4.954 & 4.732 & 0.253\end{array}\right.$ $0.1001 .000]^{\mathrm{T}} \mathrm{mm}$ (specification error $+9.7 \mathrm{~dB}$ ).

The filter was optimised using the adaptive implicit SM algorithm with the trust region convergence safeguard [cf. (6)]. We considered six candidate models, that is the coarse model of Fig. 7 with six sets of preassigned parameters as described in Table 4. The optimisation using the standard implicit SM algorithm with the candidate models used as surrogates was also performed for the sake of comparison. The termination condition was $\left\|\boldsymbol{x}^{(i)}-\boldsymbol{x}^{(i-1)}\right\|<10^{-3}$ or $\delta^{(i)}<10^{-3}$.

The optimisation results are summarised in Table 5. Fig. 8 shows the fine model response at the initial solution $x^{(0)}$ and at the final design obtained using our adaptive algorithm, $x^{(8)}=\left[\begin{array}{lllllll}36.715 & 6.026 & 5.683 & 4.324 & 0.211 & 0.100 & 0.993\end{array}\right]^{\mathrm{T}} \mathrm{mm}$ (specification error $-1.3 \mathrm{~dB}$ ).

In this example, the surrogate model $\boldsymbol{R}_{\mathrm{c} .4}$ was selected in all iterations, therefore, the final result and the number of fine model evaluations are the same for this model and for the adaptive algorithm. Note, that the surrogate model $\boldsymbol{R}_{\text {c.5 }}$ performs slightly better than the adaptive algorithm, however, the latter gives much better results than the average for all six models (around $-0.4 \mathrm{~dB}$ ). Note also that the space mapping algorithm using the most complicated model $\boldsymbol{R}_{\text {c.6 }}$ (16 parameters) was not able to find a solution satisfying the design specifications. Bear also in mind that this comparison is only meaningful after we perform optimisation on all the candidate models, which is not practical in a real situation. 
Table 5 Implicit space mapping optimisation of the openloop ring resonator bandpass filter

\begin{tabular}{|l|c|c|}
\hline \multicolumn{1}{|c|}{$\begin{array}{c}\text { Surrogate } \\
\text { model }\end{array}$} & $\begin{array}{c}\text { Specification error at } \\
\text { final solution (dB) }\end{array}$ & $\begin{array}{c}\text { Number of fine } \\
\text { model evaluations }\end{array}$ \\
\hline $\boldsymbol{R}_{\mathrm{c} .1}$ & -0.8 & 6 \\
\hline $\boldsymbol{R}_{\mathrm{c} .2}$ & -0.2 & 7 \\
\hline $\boldsymbol{R}_{\mathrm{c} .3}$ & +0.1 & 16 \\
\hline $\boldsymbol{R}_{\mathrm{c} .4}$ & -1.3 & 13 \\
\hline $\boldsymbol{R}_{\mathrm{c} .5}$ & -1.6 & 9 \\
\hline $\boldsymbol{R}_{\mathrm{c} .6}$ & +1.1 & 11 \\
\hline $\begin{array}{l}\text { adaptive } \\
\text { algorithm }\end{array}$ & -1.3 & 13 \\
\hline
\end{tabular}

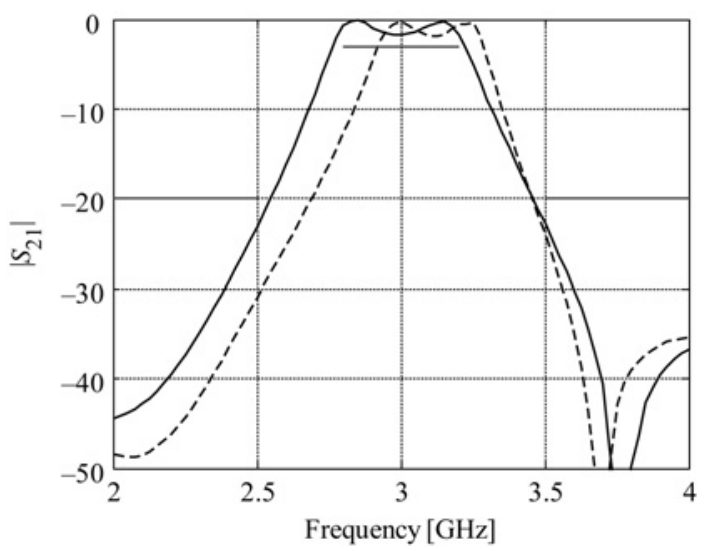

Figure 8 Open-loop ring resonator bandpass filter: initial solution (dashed line), and final solution (solid line) found using the adaptive implicit space mapping algorithm

\subsection{Wideband bandstop microstrip filter [45]}

Consider the wideband bandstop microstrip filter [45] shown in Fig. 9. The design parameters are $\boldsymbol{x}=\left[L_{\mathrm{r}} W_{\mathrm{r}} L_{\mathrm{c}} W_{\mathrm{c}} G_{\mathrm{c}}\right]^{\mathrm{T}}$. The fine model $\boldsymbol{R}_{\mathrm{f}}$ is simulated in FEKO [42]. The coarse

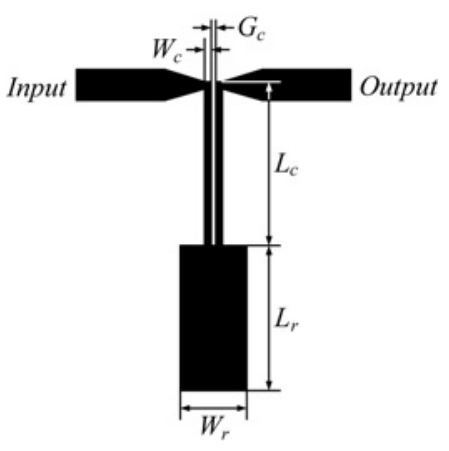

Figure 9 Wideband bandstop microstrip filter: geometry [45]

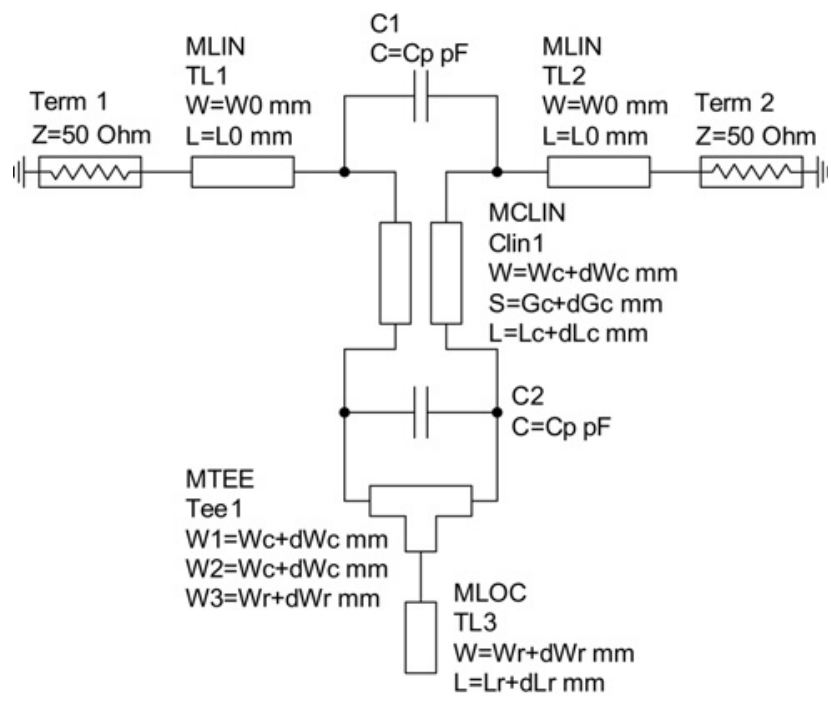

Figure 10 Wideband bandstop filter: coarse model (Agilent $A D S)$

model $\boldsymbol{R}_{\mathrm{c}}$ is the circuit model implemented in Agilent ADS [43] (Fig. 10). The design specifications are $\left|S_{21}\right| \geq-3 \mathrm{~dB}$ for $1.0 \mathrm{GHz} \leq \omega \leq 2.0 \mathrm{GHz},\left|S_{21}\right| \leq-20 \mathrm{~dB}$ for $3.0 \mathrm{GHz} \leq \omega \leq 9.0 \mathrm{GHz}$ and $\left|S_{21}\right| \geq-3 \mathrm{~dB}$ for $10.0 \mathrm{GHz} \leq \omega \leq 11.0 \mathrm{GHz}$. The initial design is the coarse model optimal solution $x^{(0)}=\left[\begin{array}{lll}7.017 & 0.980 & 8.653\end{array}\right.$ $0.0550 .109]^{\mathrm{T}} \mathrm{mm}$ (specification error $+2.9 \mathrm{~dB}$ ).

The filter was optimised using the standard implicit SM algorithm as well as the adaptive implicit SM algorithm with the trust region convergence safeguard [cf. (6)]. Seven candidate models were considered based on the coarse model of Fig. 10. Table 6 contains the description of model parameters. The termination condition was, as before $\left\|\boldsymbol{x}^{(i)}-\boldsymbol{x}^{(i-1)}\right\|<10^{-3}$ or $\delta^{(i)}<10^{-3}$. The optimisation results are summarised in Table 7. Fig. 11 shows the fine model response at the initial solution $x^{(0)}$ and at the final design obtained using our adaptive algorithm, $\boldsymbol{x}^{(3)}=\left[\begin{array}{lllll}7.327 & 0.976 & 7.985 & 0.059\end{array}\right.$ $0.099]^{\mathrm{T}} \mathrm{mm}$ (specification error $-2.0 \mathrm{~dB}$ ).

Note, that the surrogate model $\boldsymbol{R}_{\text {c. } 4}$ performs slightly better than the adaptive algorithm, however, the number of fine model evaluations required to find the solution is much larger. Again, we should remember that the real performance of a candidate model is not known unless an actual optimisation has been carried out on the model.

\section{$5 \quad$ Modified adaptive implicit space mapping algorithm}

Here, we discuss a modified version of the adaptive implicit $\mathrm{SM}$ algorithm. It is intuitively clear and has been observed in practice (e.g. [25]) that surrogate models that have too many parameters, usually allow us to obtain a better match with the fine model at any given design but may have poor generalisation capability [26]. Let us recall that the 
Table 6 Candidate model parameters used in the wideband bandstop filter problem

\begin{tabular}{|c|c|c|}
\hline \multirow[t]{2}{*}{ Candidate model } & \multicolumn{2}{|r|}{ Preassigned parameters } \\
\hline & $\begin{array}{l}\text { Number of } \\
\text { parameters }\end{array}$ & List of parameters ${ }^{a}$ \\
\hline $\boldsymbol{R}_{\mathrm{c} .1}$ & 2 & $\begin{array}{c}\varepsilon_{r}=\varepsilon_{r . \mathrm{TL} 1}=\varepsilon_{r . \mathrm{TL} 2}=\varepsilon_{r . \mathrm{TL} 3}=\varepsilon_{r . \mathrm{Clin} 1}=\varepsilon_{r . \mathrm{Tee} 1}, \\
H=H_{\mathrm{TL} 1}=H_{\mathrm{TL} 2}=H_{\mathrm{TL} 3}=H_{\mathrm{Clin} 1}=H_{\mathrm{Tee} 1}, \\
\text { other values }: C_{p}=\mathrm{d} L_{r}=\mathrm{d} W_{r}=\mathrm{d} L_{c}=\mathrm{d} W_{r}=\mathrm{d} G_{c}=0\end{array}$ \\
\hline $\boldsymbol{R}_{\mathrm{c} .2}$ & 4 & $\begin{array}{c}\varepsilon_{r}=\varepsilon_{r . \mathrm{TL} 1}=\varepsilon_{r . \mathrm{TL} 2}=\varepsilon_{r . \mathrm{Clin} 1}=\varepsilon_{r . \mathrm{Tee} 1}, \varepsilon_{r . \mathrm{TL} 3}, \\
H=H_{\mathrm{TL} 1}=H_{\mathrm{TL} 2}=H_{\mathrm{Clin} 1}=H_{\mathrm{Tee} 1}, H_{\mathrm{TL} 3}, \\
\text { other values : } C_{p}=\mathrm{d} L_{r}=\mathrm{d} W_{r}=\mathrm{d} L_{c}=\mathrm{d} W_{r}=\mathrm{d} G_{c}=0\end{array}$ \\
\hline $\boldsymbol{R}_{\mathrm{c} .3}$ & 5 & $\begin{array}{c}\varepsilon_{r}=\varepsilon_{r . \mathrm{TL} 1}=\varepsilon_{r . \mathrm{TL} 2}=\varepsilon_{r . \mathrm{Clin} 1}=\varepsilon_{r . \mathrm{Tee} 1}, \varepsilon_{r . \mathrm{TL} 3}, \\
H=H_{\mathrm{TL} 1}=H_{\mathrm{TL} 2}=H_{\mathrm{Clin} 1}=H_{\mathrm{Tee} 1}, H_{\mathrm{TL} 3}, C_{p}, \\
\text { other values }: \mathrm{d} L_{r}=\mathrm{d} W_{r}=\mathrm{d} L_{c}=\mathrm{d} W_{r}=\mathrm{d} G_{c}=0\end{array}$ \\
\hline $\boldsymbol{R}_{\mathrm{c} .4}$ & 8 & $\begin{array}{c}\varepsilon_{r}=\varepsilon_{r . \mathrm{TL} 1}=\varepsilon_{r . \mathrm{TL} 2}=\varepsilon_{r . \mathrm{TL} 3}=\varepsilon_{r . \mathrm{Clin} 1}=\varepsilon_{r . \mathrm{Tee} 1} \\
H=H_{\mathrm{TL} 1}=H_{\mathrm{TL} 2}=H_{\mathrm{TL} 3}=H_{\mathrm{Clin} 1}=H_{\mathrm{Tee} 1} \\
C_{p}, \mathrm{~d} L_{r}, \mathrm{~d} W_{r}, \mathrm{~d} L_{c}, \mathrm{~d} W_{r}, \mathrm{~d} G_{c}\end{array}$ \\
\hline $\boldsymbol{R}_{\mathrm{c} .5}$ & 10 & $\begin{array}{l}\varepsilon_{r}=\varepsilon_{r . T L 1}=\varepsilon_{r . T L 2}=\varepsilon_{r . C l i n 1}=\varepsilon_{r . T e e 1}, \varepsilon_{r . T L 3} \\
H=H_{\mathrm{TL1}}=H_{\mathrm{TL2}}=H_{\mathrm{Clin} 1}=H_{\mathrm{Tee} 1}, H_{\mathrm{TL3}} \\
\quad C_{p}, d L_{r}, d W_{r}, d L_{c}, d W_{r}, d G_{c}\end{array}$ \\
\hline $\boldsymbol{R}_{\text {c. } 6}$ & 8 & $\begin{array}{c}\varepsilon_{r}=\varepsilon_{r . \mathrm{TL} 1}=\varepsilon_{r . \mathrm{TL2} 2}=\varepsilon_{r . \mathrm{Clin} 1}=\varepsilon_{r . \mathrm{Tee} 1}, \varepsilon_{r . \mathrm{TL} 3} \\
C_{p}, \mathrm{~d} L_{r}, \mathrm{~d} W_{r}, \mathrm{~d} L_{c}, \mathrm{~d} W_{r}, \mathrm{~d} G_{c}\end{array}$ \\
\hline $\boldsymbol{R}_{\mathrm{c} .7}$ & 7 & $\begin{array}{c}\varepsilon_{r}=\varepsilon_{r . \mathrm{TL} 1}=\varepsilon_{r . \mathrm{TL} 2}=\varepsilon_{r . \mathrm{Clin} 1}=\varepsilon_{r . \mathrm{Tee} 1}, \varepsilon_{r . \mathrm{TL} 3} \\
H=H_{\mathrm{TL} 1}=H_{\mathrm{TL} 2}=H_{\mathrm{Clin} 1}=H_{\mathrm{Tee} 1}, H_{\mathrm{TL} 3} \\
C_{p}, \mathrm{~d} W_{r}, \mathrm{~d} W_{r}\end{array}$ \\
\hline
\end{tabular}

${ }^{\mathrm{a}}$ Symbols $\varepsilon_{r \text {.Elem }}$ and $H_{\text {Elem }}$ refer to the dielectric constant (initial value 3.38) and substrate height (initial value $0.508 \mathrm{~mm}$ ) of element Elem, respectively; symbols $\mathrm{d} L_{r}, \mathrm{~d} W_{r}, \mathrm{~d} L_{c}, \mathrm{~d} W_{r}$ and $\mathrm{d} G_{\mathrm{c}}$ are explained in Fig. 9

Table 7 Results of implicit space mapping optimisation of the wideband bandstop filter

\begin{tabular}{|l|c|c|}
\hline \multicolumn{1}{|c|}{$\begin{array}{c}\text { Surrogate } \\
\text { model }\end{array}$} & $\begin{array}{c}\text { Specification error at } \\
\text { final solution (dB) }\end{array}$ & $\begin{array}{c}\text { Number of fine } \\
\text { model evaluations }\end{array}$ \\
\hline $\boldsymbol{R}_{\mathrm{c} .1}$ & -0.2 & 5 \\
\hline $\boldsymbol{R}_{\mathrm{c} .2}$ & -1.2 & 7 \\
\hline $\boldsymbol{R}_{\mathrm{c} .3}$ & +1.8 & 10 \\
\hline $\boldsymbol{R}_{\mathrm{c} .4}$ & -2.3 & 15 \\
\hline $\boldsymbol{R}_{\mathrm{c} .5}$ & -2.1 & 7 \\
\hline $\boldsymbol{R}_{\mathrm{c} .6}$ & -2.0 & 7 \\
\hline $\boldsymbol{R}_{\mathrm{c} .7}$ & +2.8 & 8 \\
\hline $\begin{array}{l}\text { adaptive } \\
\text { algorithm }\end{array}$ & -2.1 & 7 \\
\hline
\end{tabular}

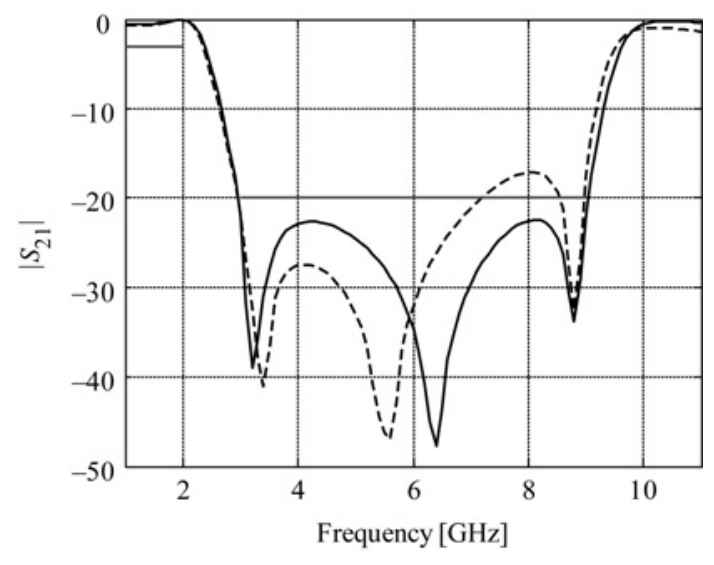

Figure 11 Wideband bandstop filter: initial solution (dashed line), and final solution (solid line) found using the adaptive implicit space mapping algorithm 
Table 8 Results of implicit space mapping optimisation of the three test problems of Section 4: modified against basic version of the adaptive algorithm

\begin{tabular}{|l|c|c|c|}
\hline \multicolumn{1}{|c|}{ Test problem } & $\begin{array}{c}\text { SM } \\
\text { algorithm }\end{array}$ & $\begin{array}{c}\text { Specification error at final solution } \\
(\mathrm{dB})\end{array}$ & $\begin{array}{c}\text { Number of fine model } \\
\text { evaluations }\end{array}$ \\
\hline bandpass filter (Section 4.1) & basic & -1.2 & 8 \\
\cline { 2 - 4 } & modified & -1.2 & 13 \\
\hline \multirow{2}{*}{$\begin{array}{l}\text { open-loop ring resonator filter } \\
\text { (Section 4.2) }\end{array}$} & basic & -1.3 & 12 \\
\cline { 2 - 4 } $\begin{array}{l}\text { wideband bandstop filter (Section } \\
\text { 4.3) }\end{array}$ & bodified & -1.5 & 7 \\
\cline { 2 - 4 } & modified & -2.1 & 15 \\
\hline
\end{tabular}

generalisation capability of the surrogate model is measured in the adaptive SM algorithm of Section 3 using the

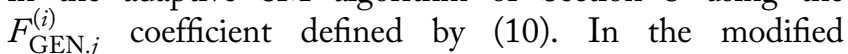
algorithm discussed here, the number of preassigned parameters of the surrogate model are taken explicitly into account while selecting the most suitable model for a given iteration. More specifically, the index $j_{\max }$ of the candidate selected to be the surrogate model, originally defined by (13) is now replaced by

$$
j_{\max }=\arg \max _{j \in\{1,2, \ldots, K\}} \bar{F}_{j}^{(i)}
$$

where

$$
\bar{F}_{j}^{(i)}=F_{j}^{(i)} \cdot f_{\#}\left(N_{j}\right)
$$

and $N_{j}$ is the number of parameters of the $j$ th candidate model and $f_{\#}$ is a user-defined scaling function. In our numerical experiments we used $f_{\#}\left(N_{j}\right)=\left(N_{j}\right)^{-1 / 2}$. This scaling function favours simpler models, but also allows us to differentiate between more complex models (i.e. ones having more preassigned parameters than design variables). For such models, the values of the combined quality factors are often very close to each other and the number of parameters becomes a good way of distinguishing between otherwise almost equally good models.

Using the modified adaptive implicit SM algorithm we solved all the problems considered in Section 4. Table 8 shows the results. For the sake of comparison, the results obtained using the basic version of the adaptive SM algorithm are also included in the table. It can be observed that the results obtained with the modified algorithm are the same or better with respect to the specification error value than the results of the basic adaptive algorithm. This confirms the intuition that simpler models (i.e. models having a smaller number of preassigned parameters) are expected to have better generalisation capability than more complex models (provided that all the models exhibit similar value of the quality factor $F_{\text {GEN. } j}^{(i)}$ and thus cannot be conclusively distinguished on that basis). However, the quality improvement may be at the expense of extra fine model evaluations as in the case of the bandstop filter. Thus, the choice of the algorithm variant should be determined by the trade-off between the required quality of the final solution and the computational complexity of the optimisation process.

\section{Conclusion}

An implicit space mapping algorithm with automatic selection of preassigned parameters has been presented. The proposed technique allows us to adaptively select a coarse model from candidates with different types and numbers of implicit space mapping parameters. Thus, our method allows us to avoid a bad choice of the preassigned parameter set and approach the best performance the implicit space mapping process could achieve without a thorough investigation of all candidate models. Its robustness is verified using several microwave design optimisation problems.

\section{Acknowledgments}

The authors thank Agilent Technologies, Santa Rosa, CA, for ADS. This work was supported in part by the Reykjavik University Development Fund, the Natural Sciences and Engineering Research Council of Canada under Grants RGPIN7239-06, STPGP336760-06, and by Bandler Corporation.

\section{References}

[1] BANDLER J.W., BIERNACKI R.M., CHEN S.H., GROBELNY P.A., HEMMERS R.H.: 'Space mapping technique for electromagnetic optimization', IEEE Trans. Microw. Theory Tech., 1994, 4, (12), pp. 536-544

[2] Bandler J.W., Cheng Q.S., Dakroury S.A., ET AL.: 'Space mapping: the state of the art', IEEE Trans. Microw. Theory Tech., 2004, 52, (1), pp. 337-361 
[3] BANDLER J.W., CHENG Q.S., NIKOLOVA N.K., ISMAIL M.A.: 'Implicit space mapping optimization exploiting preassigned parameters', IEEE Trans. Microw. Theory Tech., 2004, 52, (1), pp. 378-385

[4] KOZIEL S., BANDLER J.W., MADSEN K.: 'A space mapping framework for engineering optimization: theory and implementation', IEEE Trans. Microw. Theory Tech., 2006, 54, (10), pp. 3721-3730

[5] ECHEVERRIA D., HeMKeR P.W.: 'Space mapping and defect correction', CMAM Int. Math. J. Comput. Methods Appl. Math., 2005, 5, (2), pp. 107-136

[6] BAKR M.H., BANDLER J.W., GEORGIEVA N., MADSEN K.: 'A hybrid aggressive space mapping algorithm for EM optimization', IEEE Trans. Microw. Theory Tech., 1999, 47, (12), pp. 2440-2449

[7] BANDLER J.W., CHENG Q.S., GEBRE-MARIAM D.H., MADSEN K., PEDERSEN F., SØNDERGAARD J.: 'EM-based surrogate modeling and design exploiting implicit, frequency and output space mappings'. IEEE MTT-S Int. Microwave Symp. Dig., Philadelphia, PA, June 2003, pp. 1003-1006

[8] ISMAil M.A., SMITH D., PANARIEllo A., WANG Y., Yu M.: 'EMbased design of large-scale dielectric-resonator filters and multiplexers by space mapping', IEEE Trans. Microw. Theory Tech., 2004, 52, (1), pp. 386-392

[9] WU K.-L., ZHAO Y.-J., WANG J., CHENG M.K.K.: 'An effective dynamic coarse model for optimization design of LTCC RF circuits with aggressive space mapping', IEEE Trans. Microw. Theory Tech., 2004, 52, (1), pp. 393-402

[10] RAYAS-SÁNCHEZ J.E., LARA-ROJO F., MARTíNEZ-GUERRERO E.: 'A linear inverse space mapping (LISM) algorithm to design linear and nonlinear RF and microwave circuits', IEEE Trans. Microw. Theory Tech., 2005, 53, (3), pp. 960-968

[11] AMARI S., LedReW C., MEnZel W.: 'Space-mapping optimization of planar coupled-resonator microwave filters', IEEE Trans. Microw. Theory Tech., 2006, 54, (5), pp. 2153-2159

[12] CHOI H.-S., KIM D.H., PARK I.H., HAHN S.Y.: 'A new design technique of magnetic systems using space mapping algorithm', IEEE Trans. Magn., 2001, 37, (5), p. 3627-3630

[13] LEARY S.J., BHASKAR A., KEANE A.J.: 'A constraint mapping approach to the structural optimization of an expensive model using surrogates', Optim. Eng., 2001, 2, (4), pp. $385-398$

[14] REDHE M., NILSSON L.: 'Using space mapping and surrogate models to optimize vehicle crashworthiness design'. Ninth AIAA/ISSMO Multidisciplinary Analysis and Optimization
Symp., Atlanta, GA, September 2002, Paper AIAA2002-5536

[15] DORICA M., GIANNACOPOULOS D.D.: 'Response surface space mapping for electromagnetic optimization', IEEE Trans. Magn., 2006, 42, (4), pp. 1123-1126

[16] ENCICA L., MAKAROVIC J., LOMONOVA E.A., VANDENPUT A.J.A.: 'Space mapping optimization of a cylindrical voice coil actuator', IEEE Trans. Ind. Appl., 2006, 42, (6), pp. 1437-1444

[17] ZHU J., BANDLER J.W., NIKOLOVA N.K., KOZIEL S.: 'Antenna optimization through space mapping', IEEE Trans. Antennas Propag., 2007, 55, (3), pp. 651-658

[18] CREVECOEUR G., DUPRE L., VAN DE WAlle R.: 'Space mapping optimization of the magnetic circuit of electrical machines including local material degradation', IEEE Trans. Magn., 2007, 43, (6), pp. 2609-2611

[19] DEVABHAKTUNI V.K., CHATTARAJ B., YAGOUB M.C.E., ZHANG Q.-J.: 'Advanced microwave modeling framework exploiting automatic model generation, knowledge neural networks, and space mapping', IEEE Trans. Microw. Theory Tech., 2003, 51, (7), pp. 1822-1833

[20] ZHANG L., XU J., YAGOUB M.C.E., DING R., ZHANG Q.-J.: 'Efficient analytical formulation and sensitivity analysis of neurospace mapping for nonlinear microwave device modeling', IEEE Trans. Microw. Theory Tech., 2005, 53, (9), pp. 2752-2767

[21] ZHANG L., XU J.J., YAGOUB M., DING R.T., ZHANG Q.J.: 'Neurospace mapping technique for nonlinear device modeling and large signal simulation'. IEEE MTT-S Int. Microwave Symp. Dig, Philadelphia, PA, June 2003, pp. 173-176

[22] KOZIEL S., BANDLER J.W., MOHAMED A.S., MADSEN K.: 'Enhanced surrogate models for statistical design exploiting space mapping technology'. IEEE MTT-S Int. Microwave Symp. Dig., Long Beach, CA, 2005, pp. 1609-1612

[23] KOZIEL S., BANDLER J.W., MADSEN K.: 'Space-mapping based interpolation for engineering optimization', IEEE Trans. Microw. Theory Tech., 2006, 54, (6), pp. 2410-2421

[24] KOZIEL S., BANDLER J.W.: 'Interpolated coarse models for microwave design optimization with space-mapping', IEEE Trans. Microw. Theory Tech., 2007, 55, (8), pp. 1739-1746

[25] KOZIEL S., BANDLER J.W.: 'Space-mapping optimization with adaptive surrogate model', IEEE Trans. Microw. Theory Tech., 2007, 55, (3), pp. 541-547

[26] KOZIEL S., BANDLER J.W.: 'Coarse and surrogate model assessment for engineering design optimization with space mapping'. IEEE MTT-S Int. Microwave Symp. Dig., Honolulu, HI, 2007, pp. 107-110 
[27] RAYAS-SÁNCHEZ J.E.: 'EM-based optimization of microwave circuits using artificial neural networks: the state-of-theart', IEEE Trans. Microw. Theory Tech., 2004, 52, (1), pp. $420-435$

[28] KOZIEL S., BANDLER J.W., MADSEN K.: 'Quality assessment of coarse models and surrogates for space mapping optimization', Optim. Eng., 2008, 9, (4), pp. 375-391

[29] BOOKER A.J., DENNIS J.E., FRANK P.D., SERAFINI D.B., TORCZON V., TROSSET M.W.: 'A rigorous framework for optimization of expensive functions by surrogates', Struct. Optim., 1999, 17, (1), pp. $1-13$

[30] DENNIS J.E., TORCZON V.: 'Managing approximation models in optimization', in ALEXANDROV N.M., HUSSAINI M.Y. (EDS.): 'Multidisciplinary design optimization' (SIAM, Philadelphia, USA, 1997), pp. 330-374

[31] LEARY S.J., BHASKAR A., KEANE A.J.: 'A knowledgebased approach to response surface modeling in multifidelity optimization', Global Optim., 2003, 26, (3), pp. 297-319

[32] Gano S.e., Renaud J.E., SANDers B.: 'Variable fidelity optimization using a kriging based scaling function'. Proc. 10th AIAA/ISSMO Multidisciplinary Analysis and Optimization Conf., Albany, NY, 2004

[33] SIMPSON T.W., PEPLINSKI J., KOCH P.N., ALLEN J.K.: 'Metamodels for computer-based engineering design: survey and recommendations', Eng. Comput., 2001, 17, (2), p. 129-150

[34] QUEIPO N.V., HAFTKA R.T., SHYY W., GOEL T., VAIDYNATHAN R., TUCKER P.K.: 'Surrogate-based analysis and optimization', Prog. Aerosp. Sci., 2005, 41, (1), pp. 1-28

[35] CHENG Q.S., BANDLER J.W., KOZIEL S.: 'Combining coarse and fine models for optimal design', Microw. Mag., 2008, 9, (1), pp. $79-88$
[36] RAUTIO J.C.: 'A space mapped model of thick, tightly coupled conductors for planar electromagnetic analysis', IEEE Microw. Mag., 2004, 5, (3), pp. 62-72

[37] CHENG Q.S., BANDLER J.W., RAYAS-SÁNCHEZ J.E.: 'Tuning-aided implicit space mapping', Int. J. RF Microw. Comput.-Aided Eng., 2008, 18, (5), pp. 445-453

[38] CHENG Q.S., BANDLER J.W.: 'An implicit space mapping technique for component modeling'. Proc. 36th European Microwave Conf., Manchester, UK, September 2006, pp. $458-461$

[39] CONN, A.R., GOULD N.I.M., TOINT P.L.: 'Trust region methods' (MPS-SIAM Series on Optimization, 2000)

[40] ALEXANDROV N.M., LEWIS R.M.: 'An overview of first-order model management for engineering optimization', Optim. Eng., 2001, 2, (4), pp. 413-430

[41] HeNNINGS A., SEMOUCHKINA E., BAKER A., SEMOUCHKIN G.: 'Design optimization and implementation of bandpass filters with normally fed microstrip resonators loaded by high-permittivity dielectric', IEEE Trans. Microw. Theory Tech., 2006, 54, (3), pp. 1253-1261

[42] FEKO, Suite 5.4, EM Software \& Systems-S.A. (Pty) Ltd, 32 Techno Lane, Technopark, Stellenbosch, 7600, South Africa, 2008

[43] Agilent ADS: Version 2008, Agilent Technologies, 1400 Fountaingrove Parkway, Santa Rosa, CA 95403-1799, 2008

[44] CHEN C.Y., HSU C.Y.: 'A simple and effective method for microstrip dual-band filters design', IEEE Microw. Wirel. Compon. Lett., 2006, 16, (5), pp. 246-248

[45] HSIEH M.Y., WANG S.M.: 'Compact and wideband microstrip bandstop filter', IEEE Microw. Wirel. Compon. Lett., 2005, 15, (7), pp. $472-474$ 